\title{
Comunicación

\section{La normatividad pragmática del Talk Show y los ignorados derechos de la gente ordinaria a la imagen pública en televisión}

\author{
MARTHA RENERO ${ }^{1}$
}

En esta época de intensa desregulación mundial de los sistemas de televisión, revive en alguna medida el debate académico y político relativo a la normatividad ética asociada a la operación de la nueva plataforma televisiva. Los talk e info shows son exponentes de la pragmática del periodismo popular en televisión, que fabrica historias utilizando como protagonista a la gente ordinaria (no profesional). Este trabajo representa una aproximación preliminar a ese asunto, a partir del reporte de observaciones de un periodo de investigación de campo, destinado a elaborar datos e interpretaciones con un enfoque cualitativo.

Palabras Clave: talk shows, cultura popular, normatividad ética.
In the context of global desregulation of the systems of television in the world, there is a revival of the academic discussion about the ethical normativity of this mode of televisual production. The talk and info shows are manifestations of the popular journalism in television, which make the confection of human interest stories with the protagonism of ordinary people, without professional experience in the television making. This work is a preliminary approximation on these issues to attain the registered observations made in a stage of qualitative research on $\mathrm{El}$ y Ella, the first talk show latino made in Mexico City.

KEY WORDS: talk shows, popular culture, ethical rules.

1 Profesora e Investigadora del Departamento de Estudios de la Comunicación Social de la Universidad de Guadalajara.

Correo electrónico: martharenero@ hotmail.com. 


\section{INTRODUCCIÓN}

El debate acerca de la normatividad del periodismo impreso en Estados Unidos le ha apostado, a través de ópticas liberales, a la defensa de la moral y garantías individuales por sobre la evaluación crítica de la estructura concentradora de poder económico y político de la industria mediática. En el centro de este debate anidó la crítica al periodismo popular conocido como tabloide o amarillista que tiene larga trayectoria en los medios, pero que toma fuerza a partir de la década pasada con los noticieros de espectáculos conocidos como info-shows y los talk shows que representan ante los telespectadores el lado extraordinario de la gente ordinaria, elaborando sus historias a la manera de la prensa tabloide de más larga data y sustentando su existencia en el ejercicio de la libertad de expresión y en el derecho del público a saber la verdad acerca de las motivaciones íntimas de la gente ordinaria.

Un problema que se desea destacar en este trabajo es que las únicas propuestas normativas de la "responsabilidad social", propias del modelo liberal de la prensa escrita estadounidense, resultan actualmente sobrepasadas por la normatividad pragmática del talk show que, junto con otras variantes del realismo televisivo contemporáneo, se ha convertido en el modo predominante de producir "entretenimiento" de parte de la industria de la televisión comercial, en su intento por satisfacer la devoradora demanda de contenidos populares que solicita y hace posible el sistema satelital de televisión en múltiples países. ${ }^{2}$

Por su parte, las visiones académicas que externan inquietud ante la abundancia de contenidos "realistas" en la televisión y su tendencia sensacionalista, sugieren contrarrestar el predominio de este periodismo

2 Tal es el caso de la industria latina de televisión, cuya señal en México se ha difundido a través de los sistemas de cable de Estados Unidos como Galavisión, con contenidos producidos por Televisa, el conglomerado de medios más poderoso de América Latina, después de Globo de Brasil. Aunque líder, Televisa tiene, como toda televisora latinoamericana, hambre de dólares. Esta necesidad, impuesta por la naturaleza global del negocio de la televisión, se combina con las situaciones políticas locales y las relaciones coyunturales entre cúpulas empresariales del sector público y privado, en detrimento de la calidad de la programación para el público de esta industria. 
popular con la práctica de un hipotético periodismo civil o de investigación. Noción que permanece ambigua mientras no se llegue a consolidar un consenso en torno a las normas periodísticas mínimas que se requieren para armonizar el derecho a la información del público con los derechos al honor, la intimidad, la vida privada y la imagen pública de la gente ordinaria que protagoniza estas emisiones.

Sin embargo, mientras el sector intelectual debate este asunto, se observa que la pragmática de la producción televisiva (situada en la localidad mexicana) desconoce los citados derechos de la gente ordinaria que acude a "hacer el show" ante cámaras. En este trabajo se aborda el caso del show Él y Ella, producido por Telemundo en la Ciudad de México, con difusión prioritaria para el mercado de hispano hablantes radicados en USA, el que se ha mantenido en antena en México desde 1995 por señal de cable local. Aunque es solamente uno de los múltiples talk shows hablados en español y difundidos en décadas pasadas, con su ejemplo se observa que la industria latina resuelve con habilidad y astucia su necesidad de historias "humanas", aunque responde poco, si no es que nada, a la existencia de los derechos de la gente ordinaria que protagoniza este tipo de emisiones.

Se intenta que las prácticas productivas descritas puedan ser interpretadas como expresiones de la insuficiente normatividad ética del talk show y de su contemporáneo, el info-show, géneros pioneros de la tele-realidad en México. Se cuestionan algunos de sus procedimientos de producción, en particular su modo de convocar y manejar a los invitados durante las grabaciones en el foro de la televisora. Asimismo se comenta el manejo "populista" de parte de los dueños de las televisoras mexicanas observado

3 En el libro Tv Global, espectáculos Locales, El género de realidad en México y España, coordinado por quien esto escribe en conjunto con la Mtra. Gabriela Gómez, se sustenta que tanto el talk show como el info-show son las primeras modalidades de la tele-realidad que en la década de los noventa protagonizan los relatos extraordinarios de la gente ordinaria, contados por ellos mismos. Este protagonismo adquiere mayor resonancia y visibilidad social a través de las recientes versiones de Big Brother Vip y los shows de concurso musical como La Academia y Operación Triunfo, que cuentan con 24 horas de transmisión satelital para que el público sea espectador de la vida cotidiana de los aspirantes al estrellato. 
en el momento del retiro de antena del talk show Hasta en las Mejores Familias y del info show Ciudad Desnuda Jalisco.

Se propone colaborar con este trabajo a la construcción de consenso académico que pueda incidir en el ámbito político (en cada contexto social particular), a fin de superar los términos del debate estadounidense en torno a la "libertad de expresión", que ha sido una de las banderas que justifican a los productores de estas emisiones. Mientras esto no ocurra, es probable que el protagonismo efímero pero contundente de la gente no profesional seguirá consolidando día con día a la lucrativa y potente plataforma televisual contemporánea, que actualiza su tecnología de punta con el realismo de las historias humanas, en forma independiente del posible consenso social en torno a los límites éticos de este tipo de periodismo popular que contiene potenciales riesgos para la imagen pública de ciudadanos inexpertos.

\section{LÍMITES DE LA NORMATIVIDAD ÉTICA}

EN LA PRENSA ESTADOUNIDENSE

El principal antecedente de la existencia de un modelo ético estadounidense en el período inmediato a la Segunda Guerra Mundial fue la Comisión Americana de Libertad de la Prensa llamada Comisión Hutchins que, en 1947 y en el contexto de un mundo en ruinas por segunda vez en 25 años, reprochaba a la prensa de la época su irresponsabilidad y énfasis por lo excepcional, más que por lo representativo, y por lo sensacional, más que por lo significativo, en función de alcanzar a las mayores audiencias posibles de receptores.

Sin embargo, una década después, esta seminal comisión reguladora de la prensa dejó de lado a los posibles cambios estructurales y legales de los medios electrónicos, para colocar el énfasis exclusivamente en la moralidad y responsabilidad individual del periodista. ${ }^{4}$

4 De ahí el exclusivo llamamiento moral de publicaciones posteriores como la obra de Fred Siebert, Theodore Peterson y Wilbur Schramm, Cuatro teorías de la prensa, publicada en 1956, y la de W. Schramm titulada Responsabilidad en la comunicación masiva, publicada un año después. La influencia de estas obras seminales hizo más sólido el llamado moral hacia el amplio rango de ideas que hoy se conoce como la teoría de la responsabilidad social, Ibíd. p.106. 
Según críticos europeos como Jan Wieten (1998:101-112), la configuración histórica de la llamada teoría de la responsabilidad social de los medios masivos estadounidenses, en las décadas de los cuarenta y cincuenta, se hizo utilizando a esta teoría como el punto focal de crítica al periodismo popular conocido como "tabloide". La solución para el futuro, de acuerdo con esta posición, radicaba en la mayor profesionalización del periodismo y la imposición de controles legales a sus códigos de conducta.

Asimismo se observa que más de cincuenta años de esfuerzos reformadores desde las esferas gubernamentales y académicas no han podido forzar a la industria estadounidense de los medios a reducir sus contenidos "violentos". Así lo reporta el Centro de Estudios de la Comunicación y la Cultura en Londres, encabezado por el Dr. Robert White, quien reporta que los intentos de llegar a evidencias conclusivas sobre los efectos nocivos de la violencia televisada no han tenido una influencia significativa en las prácticas de producción de la industria. ${ }^{5}$

No se pretende obviar en este trabajo el establecimiento legal de las agencias reguladoras gubernamentales como la Comisión Federal de Comunicaciones (The Federal Communication Commission o F.F.C.), creada para proteger a los consumidores e interés público de las prácticas monopólicas de la industria privada. Éste fue y ha sido el lugar institucional desde donde se manejaron desde sus inicios (décadas de los veinte y treinta) y manejan aún, las concesiones para la operación de los medios electrónicos estadounidenses aunque, según sus críticos, sin asumir en serio la necesidad de fomentar metas educativas y culturales para la teledifusión abierta.

No solamente desde la voluntad gubernamental ha habido intentos regulatorios. Desde la sociedad civil de USA emergió el movimiento de consumidores llamado Action for Children's Television (ACT), liderado por Ralph Nader, quien cuestionó los intereses de servicio público de la industria. Esta poderosa coalición de agrupaciones ${ }^{6}$ supo cómo presio-

5 Reporta White en la revista que publica el citado centro de investigación que, en 1969, el senador John Pastore, Jefe del Sub-comité en Comunicaciones del Senado de USA, comisionó al abogado general para llevar a cabo un exhaustivo estudio sobre la violencia sin llegar a resultados concluyentes.

6 Tales grupos fueron la citada ACT, la Asociación Nacional para Mejores Difusiones, el Congreso Nacional de Asociaciones de Padres de Familia y Maes- 
nar al gobierno para que llevara a cabo acciones reguladoras. En respuesta a las presiones de estos grupos, la F.C.C. trabajó en colaboración con los industriales un programa llamado "la hora familiar", que fue criticado por la comunidad de los productores creativos, que vio en ella, además de una producción poco creativa, una nueva forma de censura que atentaba contra la "libertad de expresión".

No obstante, los industriales apelaron a las virtudes de las "nuevas tecnologías" (la difusión por cable y satélite), las que supuestamente darían satisfacción por sí mismas a las más variadas opciones. Convencieron a los políticos de que la diversidad de canales y opciones debería de ser apoyada por fuertes inversiones económicas y por la eliminación de todas las regulaciones aplicables a los servicios públicos.

En 1980 se inicia la debacle, cuando medio siglo de investigación y reformas no pudieron incidir casi nada frente a las fuerzas del libre mercado. Prevaleció la vieja institución estadounidense de dejar a estas fuerzas decidir cuáles opciones culturales se mantienen vigentes, por sobre los escasos esfuerzos previos por establecer una política de difusión de servicio público. ${ }^{7}$

\section{LA RESPONSABILIDAD ÉTICA DE LA TELE-REALIDAD}

Si bien los esfuerzos de los estados-nación han estado encaminados a delinear las virtudes de un periodismo serio, tales como la objetividad, confiabilidad, precisión y separación de las noticias de su comentario editorial, las modalidades de organización propias de la so-

tros, la Coalición Nacional contra la Violencia Televisiva y la prestigiosa Asociación Médica Americana.

7 Sin embargo, en USA existe actualmente la propuesta Mc. Bride, acuerdo que enfatiza la necesidad de parte de los medios impresos y electrónicos de dar cuenta a la sociedad civil de su responsabilidad como agentes de influencia cultural, así como de parte de esta misma sociedad de ejercer la crítica a estos medios por las representaciones que hace de asuntos como el desarme mundial, temas xenófobos y el modo como representa a la mujer. Esta propuesta aspira, según sus creadores, a rejuvenecer los círculos académicos, integrando una red de monitoreo mundial para hacer análisis de contenido de los medios, lo que permita proponer proyectos culturales a futuro. Cfr., el artículo de Kaarle Nordenstreng y otros trabajos en esta línea citados en la bibliografía. 
ciedad civil, tales como comisiones, uniones e investigaciones, parecen haber tenido poca incidencia en el periodismo impreso y tienen aún mayor problema para lidiar con las realidades de los medios electrónicos contemporáneos y particularmente con la tele-realidad, definida en este trabajo como el conjunto de prácticas productivas de la televisión de difusión Inter-continental que construye el relato televisual de historias humanas de gente ordinaria y de gente extraordinaria como artistas y realeza, cuya vida ordinaria es relatada por sus mismos protagonistas. ${ }^{8}$

Según autores daneses compilados por Brants, Hermes y van Zoonen (eds.) (1998:102), la tele-realidad designa a la producción contemporánea de televisión que no se ciñe a la narrativa de los contenidos de ficción y que, en cambio, incorpora una variedad de formatos que intentan venderle al perceptor la idea de representar la "realidad"; su reporte en vivo de eventos, así como la capacidad testimonial del medio audiovisual, son potenciados por las posibilidades técnicas de la televisión satelital que dan vida a este formato o esquema productivo.

Los académicos daneses, habituados a la influencia de un servicio público nacional de radio y televisión abierta y masiva, consideran en ocasión del retiro honorario de Denis McQuail de la Universidad de Ámsterdam, que gracias a su popularidad vertiginosa, este neo-género es el mejor exponente de la cualidad parasitaria de la televisión respecto a la prensa escrita. ${ }^{9}$ Como se trata de un género parasitario, tiene un menor estatus de legitimidad, por lo que echa mano de los recursos ex-

$\overline{8}$ Autores españoles llaman tele-verdad a este neo-género. El nombre de telerealidad es una definición que proviene de la industria francófona y el reality programming es la definición estadounidense que abarca una amplia clasificación, aunque destacan los shows de la palabra (chismes de artistas o de gente ordinaria) y los de nota roja o policiacos, que se conocen como infoshows.

9 Según Wieten, citado en Brants, Hermes y van Zoonen (eds.) (1998), el Departamento de investigación de audiencias del sistema público danés describe a este género como: “...una categoría de programas donde se muestran los eventos dramáticos y extraordinarios en la vida de la gente ordinaria...". También se refiere a la amalgama de discursos públicos y privados y a la más débil diferenciación entre hechos y ficciones, que se reflejan en la disolución de los límites entre los géneros de información y de entretenimiento. 
presivos del periodismo tradicional para aumentar su aceptación ante el gran público. ${ }^{10}$

Según este argumento, la principal forma de legitimación de este tipo de programas consiste en apelar a la clásica responsabilidad periodística del "derecho del público a saber", ${ }^{11}$ o como dice el slogan central del info-show Ciudad Desnuda Jalisco: "El noticiario que nunca le tuvo miedo a la verdad". Esta inclinación por el "destape" (que se confunde con La verdad), puede afectar el derecho a la vida privada de la gente ordinaria que protagoniza este tipo de programas, la que es representada en el límite entre la verdad que fabrican los productores y la distorsión de los problemas de la gente, lo que da lugar a actos de difamación que afectan a la imagen pública de los participantes.

Para el danés J. Wieten, la propuesta de sentido de este tipo de programación puede sugerir que cualquier persona puede ser objeto y víctima de actos violentos; no obstante, puede confiar en ser rescatada del peligro por servicios oficiales como la policía y los profesionales especialistas (médicos, paramédicos y psicólogos), siempre y cuando la ayuda sea catalizada a través del accionar de las cámaras de la televisión, encargadas de darle amplia visibilidad al "caso" con la oportunidad debida, por lo que afirma:

“...probablemente estos programas sugieren que la televisión es más confiable y representa una autoridad más humana que las autoridades tradicionales.." 12

Por su parte, Liesbet van Zoonen (1998:113-123) encuentra que el debate acerca de las reglas éticas del periodismo popular (en inglés gossip

$\overline{10}$ Wieten utiliza, para sustentar su perspectiva, un estudio de van de Westelaken (1996) "Het Maken van Reality - TV. a case-study". MA thesis, University of Amsterdam, en el que aplica la técnica de la observación participante para dar cuenta de los procesos de producción del programa Special Report con historias acerca de la vida nocturna de Amsterdam que, según el analista, tiene un equipo de principiantes del oficio en busca de causar un impacto visual en el público, en detrimento de las más mínimas normas del periodismo profesional.

11 Tomando como punto de referencia la obra pionera de Wilbur Schramm (1957), citada en Brants y cols., op. cit.

12 Ibid. p. 103. 
journalism) no ha sido sistemático ni productivo, o por lo menos no ha dado lugar a una clara propuesta acerca de cómo manejar la vida privada de la gente en televisión. ${ }^{13}$ Sugiere pensar en nuevos estándares éticos e implicaciones de una emergente vida "pública-privada" en televisión, lo que significa enfatizar la dimensión electiva de los participantes, aunque también y sobre todo, destacar las nociones de poder y estatus de la gente cuyas vidas privadas son convertidas en objeto público, deseando:

“...que la gente ordinaria que por cualquier razón se encuentre ante los reflectores de la televisión, como invitado a un talk show, como celebridad por una noche o como víctima de algún accidente, pueda ser apoyada para manejar el impacto de sus quince minutos de fama, preferentemente por los difusores de su vida privada, quienes se supone que saben qué tipo de efectos pueden esperar..." (las cursivas son mías). ${ }^{14}$

Encuentro que esta postura es utópica o deliberadamente irónica. En la experiencia de campo que se relata enseguida se observa que los difusores de vidas privadas no están interesados en los efectos -psicológicos y sociales negativos- que puedan afectar a las personas que tienen una experiencia protagónica en el foro de grabación de la televisora. En cambio, están de preferencia interesados en lo que la imagen de estos invitados representa para millones de televidentes, lo que se traduce en sintonía de audiencia, felicitaciones de las autoridades y ganancias económicas recibidas por los productores a través de bonos anuales. Por esto considero que aunque esta industria difusora y sus cuadros operativos supieran qué efectos esperar, no parecen desear asumirlos por estar fuera del ámbito de su inmediata utilidad y supuesta normatividad.

Volviendo al argumento de J. Wieten, el que la televisión tuviera mayor legitimidad social que las instituciones gubernamentales a los ojos de la tele-audiencia sería una apuesta interesante que habría que explorar en estudios de audiencia y recepción en contextos específicos. Sin embargo, ningún estudio de audiencia podría disimular el hecho de que este tipo

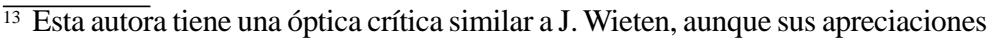
se derivan de la interpretación del rico material etnográfico generado por la corriente estadounidense de estudios empíricos sobre este tipo de programas.

${ }^{14}$ Ibid. p. 121.
} 
de programas no representa una crítica deliberada de las instituciones médicas y policiales. Asunto concomitante es la política deliberada de las televisoras por crearse una imagen de "apoyo" a la sociedad civil.

Tal es el caso de los primeros talk shows estadounidenses, llamados "pro-sociales" por algunos especialistas de habla inglesa, que les encuentran características de servicio social cuando eran difundidos a través del sistema de la radio local, antes de incorporarse a la red de la televisión nacional estadounidense, en la década de los ochenta. Sin embargo, la multiplicación exponencial de shows de este tipo hablados en un español "latino" de acento estadounidense, su difusión en horarios "no estelares" para específicos nichos de audiencia y el escándalo que les rodea, permiten leer con ironía aquella pretendida intencionalidad del talk show pro-social de décadas anteriores. ${ }^{15}$

\section{EL TALK SHOW COMO GÉNERO BAJO SOSPECHA}

A mediados de la década de los ochenta, los pioneros programas de radio se convierten en shows por primera vez y toman un lugar relevante en el sistema de la televisión abierta en USA. Programas seminales como Phil Donahue y Oprah Winfrey tuvieron sus antecesores radiofónicos. ${ }^{16}$ Hacia el fin de esta misma década se producen, además de las versiones seminales ya mencionadas, los shows de Geraldo y Sally Jesse Raphael, dirigidos a la tele audiencia de origen hispano que radica en USA. Estos últimos shows cuentan con ganancias millonarias y van en continuo ascenso de popularidad que, sin embargo, no sobrepasa a la obtenida por las ediciones más recientes, cuyo ejemplo paradigmático es el show anglosajón de Ricki Lake, lanzado al aire en 1995.

Las más recientes ediciones de este nuevo milenio que utilizan a gente ordinaria como protagonista son los llamados reality shows, que

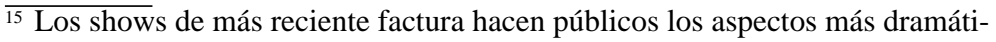
cos y escandalosos de la vida privada de los invitados, por lo que hacen parecer como cándidos abuelos a los programas de la primera época de fines de los ochenta.

${ }^{16}$ En particular, el conductor Phil Donahue tuvo como antecedente de su pionero show televisivo al programa radiofónico Conversation Piece, a través del que se pretendía atender las necesidades de la comunidad local de Ohio, USA. 
cuentan con una difusión intercontinental y con ganancias millonarias. Son emisiones posibles gracias a los avances de las telecomunicaciones y a la vaguedad de la ley federal respectiva en México, aunque este último aspecto no es objeto de este ensayo.

\section{EL “APAGAFUEGOS MORAL” CONTRA LOS TALK SHOWS}

En el mes de marzo de 1993, la ciudad de Guadalajara fue escenario de una serie de protestas callejeras, faxes y telegramas publicados en la prensa de mayor circulación local dirigidos al Presidente del país, de parte de la Alianza Fuerza de Opinión Pública, grupo de presión que integra a asociaciones como Pro-Vida, Di Basta, Asociación Nacional para la Moral y representantes del sector femenino del Partido Acción Nacional. Las demandas de estos grupos, integrados mayoritariamente por mujeres, señalaban como crítica central la incorrecta forma de hablar el castellano pero sobre todo el desprecio por los valores nacionales, sea lo que esto signifique.

Según la reseña de este evento hecha por el escritor Carlos Monsiváis (1993:46-53), el recién estrenado talk show de la conductora y productora cubano-estadounidense Cristina Saralegui ${ }^{17}$ representaba una nueva pesadilla para los guardianes del tradicionalismo. Al asumir la visibilidad televisual a fines de los años noventa, esta mujer se autopresenta como periodista por su trabajo previo como editora de la revista Cosmopolitan en español. Su show en televisión hereda, por así decirlo, la mala reputación de la prensa popular, objeto de persecución para sectores conservadores que la aborrecen, mientras que la izquierda y centro-izquierda la menosprecian, reservándole burlas y parodias.

Por su parte, el psiquiatra tapatío Fernando González ${ }^{18}$ destaca, en una brillante entrevista realizada por el extinto diario Siglo 21 de la capital de Jalisco, la sorpresa absoluta de la derecha al descubrir que los secretos del confesionario se ventilan en un programa de televisión, potencialmente visto por veinte millones de tele-receptores en la región latinoamericana. Lo que inquieta a este sector conservador, que se ma-

17 Ver bibliografía.

18 González, Fernando, entrevistado por el diario tapatío Siglo 21, en Monsiváis, Op. Cit. 
nifiesta a través de la opinión pública nacional, es la violación del secreto del confesionario, tan propio de la idiosincracia nacional de fuerte raigambre católica y conservadora, inquieta ante la posibilidad de que hayamos: “...pasado de la "amenaza comunista" que pobló el imaginario de varias generaciones a los tiempos de la ola de inmoralidad...". ${ }^{19}$

La era de la moralidad convive con la sociedad del espectáculo pues, según el escritor citado, en los tiempos neoliberales todos reformulamos nuestro concepto de éxito, acercándolo y casi fundiéndolo con el de la sobrevivencia. Por ello nos alegra cuando las cámaras de la televisión transforman una carencia o un vicio privado en el objeto de una confesión pública, pues tal vez así: “...el gobierno o alguien nos hará caso...”20

Más que hacerle competencia desleal al periodismo serio, el "realismo" televisivo le imprime la pauta central a seguir, al transformar eventos privados en asuntos públicos de manera poco atenta a los derechos de los ciudadanos representados. Lo anterior puede significar que la visibilidad pública al alcance de la ciudadanía está asociada a la falta de cauces cívico-legales para la expresión y resolución de problemas.

\section{OBSERVACIONES DE CAMPO EN ÉL Y ELLA,} UN TALK SHOW PARA HISPANOS

Se reportan en este apartado, hechos y declaraciones observados, registrados e interpretados a partir del diario de una práctica de campo, llevada a cabo por quien esto escribe, al participar como observadora de las rutinas del equipo de producción de la filial mexicana de la cadena estadounidense Telemundo Network. La sede en México estaba ubicada en los estudios Churubusco-Azteca de la ciudad de México.

Los datos considerados como más relevantes intentan responder a las siguientes interrogantes: ¿Cómo es que la industria televisiva transforma a la vida privada en espectáculo público? y ¿cómo se legitima socialmente la pretendida "ayuda" que la televisión dice brindar a los desfavorecidos? ${ }^{21}$

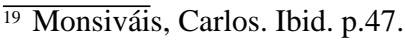

${ }^{20}$ Monsiváis, Carlos. Ibid, p.15.

${ }^{21}$ Ver en la hemerografía la tesis titulada "La vida privada como espectáculo público. El género talk show en México". 
Las siguientes son dimensiones de carácter cualitativo que tienen su referente en las declaraciones y en las prácticas cotidianas de los productores entrevistados. Se consideran relevantes porque revelan la contradicción entre las lógicas verbales y las prácticas productivas. El respeto a la privacidad de los participantes como invitados no puede ser más que una suerte de demagogia cuando se puede observar la manera como se les trata y sobre todo como se les representa. ${ }^{22}$

Como contexto explicativo se puede decir que el talk show Él y Ella fue producido en la primera parte de la década de los noventa en Los Angeles, California. En 1995 fue difundido en Guadalajara a través de una operación de importación (compra de "paquetes"), llevada a cabo por la entonces televisora independiente de Guadalajara, el Canal Super 6, empresa socia y asistente al evento anual de la National Association of TV Program Executives (NATPE) en USA.

A partir de 1996, esta emisión comienza a producirse en la Ciudad de México con personal bilingüe: por un lado, con técnicos e invitados mexicanos y, por otro, con conductores y ejecutivos "latinos", es decir, cubano-americanos y puertorriqueño-americanos, quienes venían a grabar a la capital de este país en teatros rentados por la empresa Telemundo Network, asentada en Miami (la que representa un distante segundo lugar en el mercado hispano de Estados Unidos, liderado por la empresa Univisión).

$\mathrm{Al}$ año siguiente se inaugura, en la Ciudad de México, la filial de la cadena estadounidense denominada Telemundo Studios México y se comienza a producir con personal mexicano al noventa por ciento el mismo show, siendo el par de productores ejecutivos y de conductores, el único personal nacionalizado estadounidense aunque de origen "latino" (cubano y puertorriqueño principalmente) que se queda a radicar temporalmente en este país. Los encargados de las particulares producciones son los "productores asociados", jóvenes mexicanos relacionados con el medio artístico por lazos familiares y experiencia previa, aunque con la particularidad de que la mayoría son egresados de uni-

22 Se les convoca con engaños y medias verdades, se les maneja como a personajes de una representación teatral que, sin embargo, es filmada, sin el cabal conocimiento de su presencia en el foro. 
versidades públicas, en donde estudiaron la licenciatura en ciencias de la comunicación.

De acuerdo con una supuesta reglamentación estadounidense que sigue la empresa Telemundo que opera en México desde finales de los noventa, a los invitados mexicanos se les otorga transporte y una compensación monetaria por "faltar al trabajo" el día de la grabación. Sin embargo, en la Ciudad de México, la mayor parte de los invitados declara ser desempleados, o bien, dedicarse al hogar, por lo que el ínfimo pago equivalente a 15 dólares que se les otorga por participar en este programa no representa una "compensación", sino un ingreso. Cuando la empresa mexicana Televisa produce su propio talk show en el año 2000 y 2001, este emolumento fue motivo de escándalo al interpretarse como la "mordida" aceptada por el invitado/a para "actuar" un guión.

\section{Dimensiones:}

\section{a) Reglas explícitas relativas a la ética normativa de los productores}

En esta producción pionera en territorio mexicano se inserta una académica, a quien la Productora Ejecutiva le advierte -a modo de presentación con el grupo, pero también de condicionamiento-, que:

“...hay que guardar la confidencialidad de los invitados porque en este show se trata de invitados reales, espontáneos, a diferencia de (el show) Cristina en donde los invitados son pagados, de manera que está prohibido cualquier contacto directo, sin mi intermediación, con la gente..."

En entrevista posterior, esta funcionaria explica que su actitud de desconfianza hacia la presencia de una "observadora" externa se debe a su deseo de regirse por las normas de la televisión de USA, que califica de estrictas en cuanto a la protección de la identidad de los informantes, ya que:

“....si tú los descubres en televisión, te sancionan; en cambio aquí (en México) los balconean, como es el caso de Ciudad Desnuda en donde sacan el nombre del violador (...) no es ético revelar la identidad de nuestros panelistas, pues es como si acudieran a un psicólogo y nosotros no podemos traicionar la confianza de quienes vienen al programa...." 
Esta aparente protección de la "privacidad" resultaría adecuada en relación con la naturaleza de este show, cuyo objetivo es lidiar con las "malas experiencias" de las personas. Aunque en la práctica, la privacidad de los invitados viene a ocupar un lugar secundario, porque este trasfondo afectivo y psicológico de desahogo emocional, generado en torno a los conflictos interpersonales de los invitados, es para dar sentido a la emisión, que se auto-representa como si fuera el producto de un esfuerzo coordinado para ejercer una "ayuda" institucional hacia quienes no pueden manejar con éxito su vida social y afectiva.

Ganarse el pan a través de este trabajo significa, para los jóvenes productores asociados, el tener que soportar de forma cotidiana, la manifestación de conflictos de diversa gravedad, con una asesoría legal y psicológica coyuntural y puntual para el objetivo inmediato del programa. La gravedad de los problemas de la gente, asociados al alcoholismo y a la violencia familiar en varias modalidades, se manifiesta en el foro de televisión y alivia momentáneamente la tensión. Por su parte, los productores reivindican el "lado humano" de la vida, aunque a condición de transformar los problemas de los invitados en guiones melodramáticos de "casos", para lo cual les permiten expresarse polarizando posturas en un tiempo mínimo no mayor de 3 minutos. ${ }^{23}$

La supuesta "utilidad social" de este tipo de emisiones está justificada en uno de los pilares de la tradición industrial de los medios, ya que desde la radio hablada existe el interés de los productores por explotar comercialmente este "lado humano". Sin embargo, sorprende que ésta sea una creencia sostenida a todos los niveles de la empresa en cuestión, desde los más altos directivos hasta los más insignificantes asistentes de los productores asociados, por lo menos ante esta entrevistadora. El entonces Vicepresidente de producción de la cadena Telemundo, entrevistado en la inauguración de su filial mexicana, sintetiza esta postura:

“...lo que se intenta con programas como éste es darle oportunidades a la gente de plantear una situación personal que está viviendo y traemos a

$\overline{23}$ Tiempo promedio de expresión por cada invitado, cuando hay un promedio de seis a ocho invitados. Tiempo que comparten con las intervenciones de los conductores para ajustar 40 minutos de contenido y 20 minutos de comerciales en cada emisión. 
algún especialista a tratar de ayudar a resolver esa situación; son muchas las personas en su casa que han pasado o están pasando por una situación similar y definitivamente, éste es un proceso de ayuda y educación para este tipo de audiencia..."

La productora ejecutiva de este show en particular refuerza esta posición de supuesto servicio a la comunidad:

“...este show está hecho para gente que no tiene acceso a psicólogos, ni a terapeutas y que, sin embargo, tiene que resolver un problema; entonces nosotros les damos la oportunidad para que hablen, lo que de otro modo no hacen, pero nunca les decimos qué tienen que hacer, ésa es su decisión..."

El conductor principal ("host" en inglés) hace referencia en entrevista a un "caso" en donde una joven menor de edad con el vientre abultado de ocho meses de embarazo, le pide perdón a su padre por haber huido de casa: ${ }^{24}$

Conductor: “...lo importante no es tanto la gente que está ahí en el foro, sino la que nos ve en casa, la que dice: “..si Janete no se atrevió, yo sí me atrevo..."

Productora ejecutiva: “...por cada panelista y dependiendo del rating, hay entre 800 a cuatro mil personas que están representadas en cada panelista; no somos psicólogos (...) aunque también tenemos que hacer un show que nos dé de comer..."

Se observa que, en un momento previo a la grabación de uno de los programas grabados en la sede mexicana de Telemundo, la citada funcionaria se encuentra por primera vez con "Julia", ${ }^{25}$ una joven invitada

${ }^{24}$ Cuando conocí directamente el contexto más amplio de esta familia, todo indicó que ese padre de conducta violenta y afición al alcohol había sido en gran parte responsable de la "huida" de su hija menor de edad, ante la pasividad de la esposa. Un año después de esta entrevista registré que la segunda hija de este matrimonio siguió los pasos y hasta superó el proceder de su hermana mayor, quedando embarazada desde los 15 años.

${ }^{25}$ Nombre ficticio. 
que estuvo cerca de fallar a su compromiso de asistir al programa por causa de los golpes que le propinó su amante, algunas horas antes de la grabación del programa. Al ser invitados al programa, las tensiones estallaron en esta relación conflictiva entre madre-hijo-nuera, por lo que el joven "defendió" a su madre de los insultos de su amasia, propinándole golpes en las piernas y negándose a asistir a la grabación.

La Productora ejecutiva dijo a Julia, ante la ausencia de su suegra, que había cuatro mil personas en su misma situación y que debería superar su dolor para denunciarlo por haberla golpeado. La joven terminó confesando que quería asistir al programa pero no para denunciar a su agresor, sino a su odiada suegra.

De cualquier modo, interpreto que esta cifra de las cuatro mil personas confirma la aritmética del rating; al ver los moretones que esta mujer tenía en las piernas, la funcionaria probablemente pensó obtener el mayor puntaje posible de sintonía de audiencia. La dudosa disposición de Julia de asistir al programa a mostrar los golpes dados por su amante ante cámaras probablemente fue el motivo del discurso y serie de consejos que le fueron dados a esta joven del estado de Puebla, por la funcionaria puertorriqueña-americana, quien para dar consejos sacó a relucir su propia experiencia en el trato con los hombres agresivos. Sin embargo, se observó que la actitud tímida de esta invitada horas antes de la grabación del programa contrastó con su actitud desinhibida ante cámaras al exhibir de forma "voluntaria" los golpes recibidos, con el fin de ganar el favor del público presente en el foro y dejar en evidencia a su suegra enemiga, no así a su amante que no acudió al show.

Como este "caso", se observó que es intensa la presión colectiva de parte de los productores para que el/la invitado/a "escupa la verdad". Se trata de conflictos agudos y situaciones límite que favorecen el abuso de autoridad, lo que apenas se ha comenzado a documentar. ${ }^{26}$ En esta práctica de campo se pudo observar que son varios los factores que coinciden para ejercer esta presión sobre gente inexperta en el manejo actoral, quienes acuden a enfrentar a un rival o a desahogar un conflicto personal siendo observado/a por unas doscientas o más per-

${ }^{26}$ Con trabajos como el de Joyner P.P. y Dominick, J.R. (1994), indicados en la bibliografía. 
sonas desconocidas presentes como audiencia viva en el foro. Cegado/a por sus propios conflictos y ante luces intensas deberá intentar responder al alud de preguntas que los conductores hacen para conocer sus "verdaderos motivos". Esto sin contar con el condicionamiento que reciben antes de la grabación del programa mediante los citados consejos. Se trata de una situación de extrema vulnerabilidad que los productores olvidan después de la grabación del show porque termina la vida útil del "caso", no así los participantes directos y sus denunciados.

Por otra parte, mientras los más asiduos psicólogos/as a este show dicen concordar en que sí hay un efecto catártico en los invitados: “...pues hablan y descansan, aun sin experto...", otros profesionistas con mayor trayectoria profesional y no tan hambrientos de visibilidad mediática señalaron estar sin su consentimiento en la lista de "asesores" del programa. Por ejemplo, el Dr. Ramón Esteban, entonces director de la Clínica para la Atención y Prevención de la Violencia, A.C. (CAPREVI), afirma en entrevista que en tal tipo de programas no hay ningún efecto terapéutico y sí, en cambio, hay abuso de autoridad en diversos grados, además de la descalificación de la labor realizada por asociaciones civiles que trabajan a favor de la salud mental en este país:

“...la psicoterapia no la va a hacer uno en televisión, quien esté pensando eso está súper equivocadísimo, ahora se ha vulgarizado terriblemente (...), ya hasta Alfredo Palacios usa psicoterapia y regaña a la gente (...), con la ligereza que trata los temas, engañando a la gente, lastimándola y tratándola de estúpida (...) hay muy poca cultura psicoterapéutica, Palacios no sabe que existe el Instituto Mexicano de Psiquiatría, de Psicoanálisis, diversas organizaciones gubernamentales, círculos psicoanalíticos, salud mental para universitarios..."

La aparente loable labor de "dar voz a los sin voz" no es desinteresada. Esta especie de "terapia pública" tiene una justificación central que es la sintonía de la gran audiencia en USA, compuesta en forma mayoritaria por población de méxico-americanos y de migrantes que hablan español, que se sienten desarraigados y que residen en los barrios más poblados de ciudades como Los Angeles, Chicago y San Antonio en aquel país. 
Pocos años después en México, estas emisiones, producidas en forma pionera por la empresa estadounidense de cultura latina, se convierten a través de la señal abierta de la televisión comercial en un espectáculo que busca de manera aún más deliberada el favor de la gran sintonía. Lo hace a través de la representación de personajes grotescos y actores sin identidad, que desfilan ante las cámaras en la última emisión al aire arrancándose el disfraz de bestias peludas. ${ }^{27}$ La racionalidad económica de los funcionarios de la televisión comercial mexicana es firme, mientras más humor o vacilada, mayor es la sintonía del gran público. Cosas de la televisión abierta en este país.

Como lo declaró el cubano Federico Wilkins, productor de este polémico talk show del grupo Televisa:

“...el programa Hasta en las Mejores Familias desprecia la falsa moral de los programas que dan consejos. No es posible que un psiquiatra dé un dictamen en cinco minutos sobre un desconocido. Nosotros tenemos una actitud más cívica; por eso los que opinan se llaman "metiches" y no son jurados serios, ¿cómo pensar que una persona va a tomar la decisión de su vida en un programa de televisión...?. ${ }^{28}$

El desafío sarcástico, teñido de humorismo populachero lanzado por este productor, desprestigió la supuesta orientación social de los clásicos talk shows estadounidenses y latinos que desde décadas anteriores prometieron al público una ayuda desinteresada a sus problemas.

\section{b) Normas implícitas en torno al manejo de los invitados como protagonistas}

El aserto de que los periodistas son manipuladores, a la vez que actores manipulados por el reinado indiscutible de la rentabilidad económica o rating, es sostenido lúcidamente por el finado sociólogo francés Pierre

${ }^{27}$ Ocurrida el 21 de febrero de 2001, después de quince meses de tupidas protestas de grupos de presión, autoridades varias y telespectadores que sentían afectados sus intereses con esta emisión que se burlaba de la ayuda terapéutica y hacía predominar el chisme y la difamación de personajes ficticios que ocuparon el lugar de la gente ordinaria.

${ }^{28}$ Entrevista a Federico Wilkins realizada por el periodista José Antonio Fernández. Ver la hemerografía. 
Bourdieu (1997). A diferencia del aparente celo por guardar la privacidad de los invitados ante una observadora externa, en este apartado se describe una serie de movimientos del equipo de producción que son susceptibles de infringir los derechos de los invitados/panelistas a la imagen, honor y privacidad, lo que apoya la argumentación del sociólogo francés que, sin embargo, no se abordará en detalle en este ensayo.

Las normas implícitas de la producción se definen como las acciones que integran una práctica social que se considera "discursiva", porque habla a través de las acciones articuladas de un conjunto de agentes institucionales. Con fines analíticos, estas normas han sido inferidas a partir de las observaciones realizadas en este periodo de campo y elaboradas como "datos". Para fines de este trabajo se describen algunas de las prácticas relacionadas con el manejo de los invitados, en tres momentos sucesivos que son la convocatoria, la estancia en el foro de grabación y el seguimiento posterior en sus domicilios o en consulta psicológica.

\section{b.1.) Condiciones para participar. Fase de la convocatoria}

Según el citado Dr. J. Gamson (1998), en la televisión estadounidense a los invitados se les prepara para salir al foro de grabación por medio de la acción de algunos agentes de la producción que, minutos antes de entrar en escena, los "estimulan" de diversas maneras para que expresen lo que la producción espera que manifiesten respecto a "su problema". ${ }^{29}$

Se observó que los noveles productores del talk show reportado en las notas de campo están sumidos en un ambiente de fuerte competencia para producir los "casos" más impactantes, echando mano de casi cualquier recurso. En las juntas semanales, estos jóvenes eran invitados por su jefa a "producir veneno con visión". Esto significaba convencer a la gente de acudir al programa a exteriorizarse, aun cuando éste no era visto por televisión abierta en el mercado mexicano. ${ }^{30}$

${ }^{29}$ A estos agentes clandestinos, cobijados en el equipo de producción, se les llama "fluffers" en inglés, porque son como una pluma que sutilmente hace cosquillas y puede provocar el estornudo o, bien, la exteriorización de una determinada conducta agresiva.

${ }^{30}$ Carente de convocatoria nacional, este show tenía serias dificultades para llenar el foro de grabación con un promedio de 200 personas de ambos sexos conocidas como "audiencia viva". 
Por otro lado, la actitud reservada de los productores asociados de este show impidió, a quien esto escribe, la oportunidad de observar directamente cuáles son los procedimientos para llevar a cabo el reclutamiento de los invitados. Unicamente se observó que gran parte de esta labor se hace personalmente a través de las mujeres que acostumbran reclutar invitados, llamadas "busca-panelistas", y luego se hace vía telefónica, entre los seleccionados por estas mujeres y el/la productor/a responsable de la emisión particular.

El testimonio de una de las mujeres que buscan invitados llamados "panelistas" confirma que la provocación es un modo frecuente de convencer a la gente para que acuda en busca de "ayuda":

“...se trata de desahogar ciertas cosas que traemos dentro, si son unas cuñadas y no se pueden ver y se odian a muerte, a lo mejor una me dice: “...yo sí quiero ir a ese programa porque ahí le va a ir (mal a su cuñada) (...) y le voy a dar (golpear), y la otra igual, entonces ya sé, esto va a estar bueno, porque pues va a haber agarrón ¿no?...” (las cursivas son mías).

Por su parte, los productores asociados hacen labor para obtener el consentimiento de los invitados, lo que conviene a sus fines. Por ejemplo, uno de ellos habla en entrevista de cómo le hace para convencerles:

“....cuando tú (productor) hablas por teléfono con ellos (invitados), cuando les haces la entrevista hay ciertas cosas que ellos ya olvidaron y tú les mueves, es decir: "Oye ¿recuerdas cuando tu hijo te pegó?”, “i ahhhh!” (respuesta de enojo del entrevistado) y aunque ya lo superaron o aparentemente ya lo pasaron, de repente, ese... rencor o esa agresión vuelve a salir y dicen: "...mañana (en el show) me desquito..."

Además de las motivaciones para el desahogo de rencores, se pudo observar en la preparación de esta emisión que los agentes de la producción daban informaciones divergentes a los invitados convocados para representar un mismo "caso". Una invitada que fue hospitalizada por el estrés sufrido durante la grabación de su "caso", en el que ella junto con sus hijas maltratadas desafían y desenmascaran públicamente al esposo golpeador, manifiesta en entrevista lo que le dijo la "busca-panelista" para convencerla de acudir al programa: 
“...me dijeron que si tenía un problema, entonces yo les dije que sí, que si me podían ayudar a resolverlo porque ya no podía más, entonces ya vino la señora Rocío, ya le dije de qué se trataba y ya me dice bueno, '....usted va a ir a este programa y a su esposo lo vamos a llevar de sorpresa, él no va a saber nada, ya nomás cuando esté allá ya le vamos a decir por qué...”,

Se pudo constatar, en el transcurso de la grabación, que los productores asociados mantenían aislados a los invitados, haciéndoles esperar antes de salir al foro en habitaciones separadas mientras los maquillaban y colocaban el sistema individual de audio, dándoles la información al modo que convenía a la producción, sea para revelar secretos o para estimularlos a pelearse.

\section{b.2.) Estancia durante la grabación en el foro}

Una vez iniciada la grabación del show se observa que, en las pausas que se hacen entre la grabación de los diferentes segmentos, el productor asociado respectivo decía a quienes manifestaban sentir miedo de sus familiares, que podían decir todo lo que quisieran de sus agresores, porque éstos no los podían oír. Después de obtenida la confesión en cámara, los productores hacían que los acusados de ejercer violencia cotidiana contra los invitados denunciantes (en el segmento previo a los últimos comerciales), ingresaran al foro sin saber a qué venían, para enseguida ser cuestionados por los conductores ante un público vivo que manifiesta sus rechazos a coro, con rechiflas, gritos y gestos. Estas situaciones representaban riesgos no sólo para los participantes, sino para los mismos productores, tal y como lo declara una de ellas:

“...a las amantes es muy fácil convencerlas, el panelista y la amante platicamos y les dije que vinieran al programa, pero fui y le dije lo mismo a la esposa, sin que el esposo supiera, y también vino (al programa) y entonces el hombre furioso me buscaba (decía): 'Quiero ver a Rocío porque no me dijo que iba a invitar a mi esposa', entonces yo me subí en el público (gradas del foro de grabación) y no me fui hasta que no se los llevaron (a los panelistas en la camioneta de la compañía televisora)..."

El elemento tecnológico encarnado en el apuntador electrónico es lo que permite vincular las dinámicas del foro de grabación y de la uni- 
dad de control maestro, ubicada en el exterior del primero. Este sistema de audio no solamente facilita las órdenes de los jefes situados en dicha unidad a los subordinados ubicados en el foro, sino que transmite información en ambos sentidos, también de los subordinados a los jefes, como cuando los camarógrafos le "dan la toma" al director de cámaras y cuando el conductor critica en inglés a los invitados, a través del sistema de audio que sólo pueden escuchar los productores. Enseguida, el camarógrafo principal coincide en que hay que improvisar haciendo las tomas sobre la marcha de la grabación del programa:

“...hay que darle la toma al Director de Cámaras, pues éste tiene enfrente seis cámaras y le es difícil ver los detalles, entonces uno que está en contacto con el público afoca (sic) a ciertas expresiones que luego se suitchean (sic)..."

El cuestionado dispositivo de la "tele-vigilancia" se aplica aquí en forma cotidiana sin ninguna norma ética, a fin de obtener información y resolver situaciones sobre la marcha de la grabación, las que pueden afectar lo previsto en las juntas de planeación, pues según el mismo informante:

“...hay veces que, en un corte, dejo la cámara en los panelistas que siguen discutiendo y como tienen el audio en "on" (encendido), pues les dejo la cámara y yo me doy la vuelta para que los vean y los oigan allá arriba en el camión..."

Se registraron varias historias en las que estos micrófonos encendidos captaron las amenazas de algunos invitados hacia otros. Los abusadores les decían a sus víctimas que llegando a casa se vengarían de éstos. Al ser escuchadas dichas amenazas por los productores desde la unidad móvil, éstos se las comunican a los conductores, para que cuando se reinicie la grabación del siguiente segmento de emisión, el conductor haga explícito ante cámaras que "todos" escucharon las amenazas, por lo que indica a los abusadores que serán vigilados por el personal del programa durante las semanas siguientes a la grabación, cosa que no ocurre.

Se trata de una compleja situación en el foro de grabación que incorpora interacciones cara-a-cara entre el conductor y los invitados, entre la 
audiencia viva y el conductor, entre los invitados y la audiencia viva. ${ }^{31}$ Para quienes pisan el foro por primera vez como invitados-protagonistas, las cámaras están ahí pero son un elemento secundario, porque ésta es una experiencia sentida como "personal". Para este tipo de invitados de escasos recursos materiales, afectivos y linguísticos, lo importante es la figura del conductor como autoridad moral ante el familiar, el amigo o el enemigo presentes en el foro $\mathrm{y}$, como fondo, no pueden dejar de advertir las reacciones colectivas de la audiencia viva a la que, por cierto, se le dejaba participar ante micrófono con una mínima frecuencia.

La actuación del conductor hacia los Invitados y la inexperiencia de éstos para actuar ante las cámaras es lo que mantiene vivo a este show. Por su parte, el conductor "actúa" como si la sensación de los invitados neófitos fuera la realidad, como si se tratara de un momento de intimidad y las cámaras no existieran, a fin de lograr esa confianza y "destape" del invitado. ${ }^{32}$

Por todo lo descrito, cada grabación, por más tecnificada que sea, pone en vilo a tres equipos de producción y a un promedio de 250 personas profesionales y otros tantos invitados que son gente ordinaria, no profesional, en un juego simultáneo de planos técnicos y culturales de existencia, que ninguna teoría sociológica ha explicado hasta el momento en forma satisfactoria. Detrás de la tecnología descrita se ubican las perspectivas culturales de los productores "latinos", quienes, desde sus prejuicios de clase y cultura, creen saber cómo tratar problemas sobre la infidelidad, sado-masoquismo, violencia familiar y alcoholismo. Desde su perspectiva conciben el show como un nudo dramático, cuyos ingredientes son preparados de antemano para que los invitados "exploten" ante cámaras.

${ }^{31}$ La gente ordinaria que actúa en el foro de grabación parece no tener conciencia de que, desde la unidad de Control Maestro (situada en el exterior del foro, en un camión sin acceso general), los productores ejecutivos y el coordinador de la "audiencia" dan órdenes, dirigen a través del sistema de micrófonos, como si se tratara de directores de orquesta, la escena que la gente experimenta como 'personal' y hasta 'íntima", .

${ }^{32}$ En cambio, la conductora no es capaz de involucrarse con los invitados más allá de algunas frases estereotipadas y todo el tiempo se le ve preocupada de "retratar" bien ante la cámara. 


\section{b.3.) Seguimiento de los invitados-problema}

Salir de "panelista" tiene sus riesgos, pues la visibilidad pública que se adquiere puede acarrear consecuencias no favorables. Se puede quedar en un estado de indefensión legal frente a los productores, pero sobre todo respecto al familiar con quien se tienen problemas. La señora "Lupita" participó como panelista con la intención de acusar públicamente a su ex esposo por su mal comportamiento hacia ella y sus hijos y con ello acelerar su trámite de divorcio. Dice que el programa le sirvió de desahogo a su familia contra el hombre, quien les amenazó con vengarse de ellos. La tensión nerviosa del enfrentamiento la obligó a hospitalizarse un día después de la grabación del programa. Entrevistada en su casa, esta mujer está consciente de que después del programa los productores dejaron de interesarse en su caso, en consecuencia teme correr el mismo peligro que externó una invitada que participó en el programa de la señora Silvia Pinal: ${ }^{33}$

“....como lo que le pasó a la señora, llega la señora a su casa (después del programa) y llega el hombre, la agarra, la amarra y le prende lumbre, la quema y le está gritando, le empieza como loco a gritar: 'Me fuiste a poner en mal en tu dichoso programa y ahí estás, aquí pagas lo que me hiciste', y diga usted ¿quién la defendió?..”

Resulta fácil mentir y convocar con engaños a los invitados, ya que no existe ninguna regulación legal y protección psicológica ante el efecto que les cause la escenificación de sus problemas ante las cámaras. En particular, carecen de protección ante las represalias que puedan recibir de parte de algún familiar que quede molesto al ser "descubierto" contra su voluntad ante el público en el foro de grabación (aun si no hay conciencia del público en casa).

Por otro lado, se pudo constatar que el prometido seguimiento a los “casos" es una ficción. Una vez grabado el programa, la gente que

\footnotetext{
33 "Mujer, casos de la vida real" conducido por la señora Pinal es un tele-teatro que ha batido récord de permanencia en antena en México. La actriz que se dio a conocer como icono del cine mexicano en los años treinta, ha tenido una larga trayectoria artístico-política, de ahí su posible autoridad moral ante los televidentes.
} 
sigue con el mismo problema intenta comunicarse con el productor y éste deja de estar disponible para el invitado. En forma personal, la mayor parte de las ex participantes entrevistadas de este show, respondieron no haber tenido después del programa ningún tipo de apoyo moral ni legal de parte de la producción. La que, en cambio, presumía de brindar servicio psicológico en forma gratuita a los invitados, lo cual era cierto, pero solamente para una sola consulta. Aun así eran muy pocos quiénes acudían a esta única cita pagada por la producción.

\section{LA SALIDA DE ANTENA DEL INFO SHOW \\ CIUDAD DESNUDA JALISCO}

Similar escándalo, asociado a la presencia en antena de los talks shows de factura nacional, ocurrió en relación a la cancelación "sorpresiva" de este info-show de factura local (tapatío), el que marcó pauta al hacer ganar a la filial de Tv Azteca en Guadalajara los mayores puntajes de rating de su historia. Ciudad Desnuda es el nombre de esta emisión que se dejó de transmitir en el mercado nacional mexicano sólo cuando dejó de producir ganancias. El análisis de esta emisión hace afirmar a la investigadora Gabriela Gómez que:

“..transgrede la ética al provocar las lágrimas de la gente que está sufriendo (...) al prometer aunque de manera no explícita la ayuda social, cuando su función no es ésa y, sobre todo, al mercantilizar con el dolor humano, con el dolor de la gente pobre que es la protagonista (...) ¿cómo podía 'defenderse' la madre que se encontraba en el funeral de su hijo, cuando el reportero quería entrevistarla y ella no lo deseaba?". ${ }^{34}$

Todo marchaba sobre ruedas cuando la filial en Guadalajara de la televisora Tv Azteca registraba una histórica sintonía y, por tanto, un refrescante ingreso económico. Es precisamente cuando el entonces presidente del país Ernesto Zedillo declaró a la prensa su preocupación como "padre de familia" y no como estadista, por los crecientes "conte-

${ }_{34}$ Tesis de Maestría en comunicación de Gómez Rodríguez, G. (2002), en la hemerografía. 
nidos violentos" de la televisión mexicana. De esta queja pública al retiro de antena sólo pasaron algunos días. ${ }^{35}$

Cabe decir que el impacto de su retiro del aire creció al escenificar en las calles un carnaval de despedida transmitido en directo a nivel nacional, con la participación de varios cuerpos policíacos (policía montada y motorizada). Las notas de la emisión de despedida, registradas en la tesis citada, convertía este hecho del marketing en un gran acontecimiento social enunciado con el acostumbrado tono tremendista del programa.

Con este homenaje "a toda máquina" y otras manifestaciones organizadas e interesadas propias del fervor popular mexicano, tanto el info show como el talk show, se muestran como catalizadores de una ayuda pública, cada día más demandada y a todas luces insuficiente. Estos programas de clara tendencia "populista" tienen una vida efímera, la que, sin embargo, les es reciclada mediante la conjunción de los recursos del poder mediático, en beneficio de la concentración económica y de la inclusión de la sociedad civil solamente como protagonista de un periodismo tabloide.

\section{LAS DENUNCIAS Y ATENTADOS AL DERECHO AL HONOR}

Una revisión de notas aparecidas en la prensa capitalina durante los años 2000 y 2001, que no es la intención reproducir en detalle en este momento, indican la presencia de algunas denuncias penales contra los responsables de este tipo de producciones realistas de las televisoras mexicanas. Entre éstas destacan las denuncias penales y demandas por daño moral giradas entre los representantes de Tv Azteca y los responsables de las producciones particulares ante el Ministerio Público de la ciudad de México y la Comisión Nacional de Derechos Humanos, en torno a la grabación y difusión nacional de una serie de robos "actuados" y sobornos tanto a autoridades de tránsito como a menores

35 El noticiario que nunca le tuvo "miedo a la verdad" estuvo en antena en señal abierta poco menos de un año. Su éxito de sintonía se atribuye a su capacidad de evocar los peligros propios de la localidad urbana, al uso de la señal satelital 080 del Centro integral de comunicaciones y a la colaboración explícita de organizaciones estatales como los cuatro cuerpos de policía de Guadalajara y los principales centros de atención médica. 
infractores de la calle para ilustrar prácticas de tortura y corrupción en los info-shows Ciudad Desnuda, Metrópolis y Hechos de la Mañana. ${ }^{36}$

Respecto a los talk shows se registran en este mismo periodo un par denuncias por el delito de difamación de parte de personas ordinarias, que aceptaron ser pagadas para actuar un papel de degenerados y amorales en el show Cosas de la Vida de la misma emisora, lo que les atrajo el repudio de su comunidad y motivó para levantar la posterior denuncia. ${ }^{37}$ Asimismo, llama la atención la denuncia contra este mismo programa por difamación y delito contra el honor y responsabilidad profesional que en antena calificó de "secta satánica" a la religión mormona de una invitada. ${ }^{38}$

Los casos anteriormente mencionados no consideran el análisis de las quejas de oficio de instituciones como la Comisión Nacional de Derechos Humanos ${ }^{39}$ y otras contra estas emisiones. En cambio, resaltan el atentado de la citada televisora contra el derecho al honor de los invitados. El analista de medios Genaro Villamil define este derecho como aquél cuyo objetivo es proteger la dignidad de la persona reflejada en la imagen que se proyecta a los demás (en este caso al público) y la consideración de sí mismo que tiene la propia persona. ${ }^{40}$

\section{VISIONES ACADÉMICAS ANTE LA CRECIENTE VISIBILIDAD DE LA “VIDA PÚBLICA-PRIVADA"}

De vuelta al asunto relacionado con las posibilidades de normar la actividad y contenidos de los medios electrónicos contemporáneos, habría probablemente que matizar el deseo de servir a un imposible "interés público", optando en cambio por la posibilidad de obtener un mayor

$\overline{36}$ Notas de prensa en el diario La Jornada a lo largo de los días 5,8,10,15,18,21 y 24 de julio de 2000, 7 de septiembre del mismo año y 5 de enero de 2001 . Ver la hemerografía.

${ }^{37}$ Nota aparecida en el diario Excélsior de la Ciudad de México el 21 de febrero de 2001, reproducida y ampliada en la revista mensual Etcétera de marzo de 2001. Nota en el diario La Jornada del 24 de mayo del mismo año.

38 Diario La Jornada del 25 de mayo de 2001.

${ }^{39}$ Diario La Jornada del 23 de septiembre de 2000.

40 Diario La Jornada del 29 de abril de 2001. 
protagonismo de la sociedad civil en la gestión de los medios electrónicos y la satisfacción de "intereses públicos". ${ }^{41}$

Según la autora holandesa Ien Ang (1998:77-88), al pensar el futuro de los medios desde una perspectiva del interés o intereses públicos es necesario mantener un sentido de realismo, en lugar de tratar de imponer normas y expectativas generales y poco realistas, que lo único que han hecho es alimentar históricamente a las expresiones públicas de "pánico moral". En esta perspectiva, se trataría entonces de alimentar un continuo proceso de dar voz a particulares problemas, en particulares momentos, cuando las circunstancias políticas y sociales lo demanden, lo que podría ser la tarea de los intelectuales interesados en el bien público.

Para el investigador estadounidense George Gerbner (1998:135146), una alternativa de acción ante este panorama preocupante del predominio del periodismo tabloide sería el tratar de apoyar la voz de los ciudadanos independientes en la elaboración de políticas públicas, a la manera del Movimiento por el Medio Ambiente Cultural que promueve en USA la acción ciudadana en varios frentes. Entre éstos se cuenta el apoyo a toda iniciativa de la sociedad civil para abolir la concentración de la propiedad y la censura en la vida pública y privada. El movimiento citado no se queda ahí, también incluye propuestas para la creación de una posible política cultural en la agenda públicapolítica, la promoción de la organización de periodistas, escritores, directores, productores y otros trabajadores creativos de los medios, para que éstos tengan mayor margen de negociación a la hora de representar la vida privada como una mercancía para ser consumida por los mercados intercontinentales de telespectadores. Por último, es deseable apoyar el refuerzo de iniciativas de educación para la recepción y la lectura crítica de los medios.

Sin embargo, para Cees J. Hamelink (1998:66-75), el devastador impacto del mercado capitalista y el decremento en estatus y calidad de la labor académica y de investigación obstaculizan seriamente la inde-

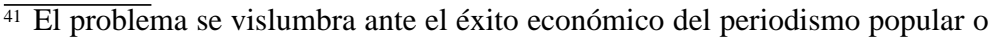
tabloide, que hace revivir demandas reglamentarias relacionadas con el derecho a la información, las que, como se mencionó, no fueron aplicables al periodismo impreso de décadas pasadas, el que creció su vocación tabloide en la misma proporción que recibía las críticas moralistas. 
pendencia y reflexión creativa de los estudiosos de la comunicación, quienes -propone- deberían promover un espacio para la creatividad e independencia intelectual capaz de apoyar, en lo posible, la construcción de un hipotético orden mundial de comunicación y la actualización de sus mejores ideas normativas.

\section{CONCLUSIONES}

Se aborda a través de este trabajo un fenómeno emergente, producto de la compleja confluencia de impresionantes desarrollos tecnológicos, concentraciones de poder económico y político, hegemonía de los sistemas comerciales de televisión, necesidad de códigos emocionales universales, creciente inseguridad pública mundial, desprestigio de autoridades estatales, falta de políticas públicas de bienestar social y, por último, desinterés de la gente ordinaria en actividades de la esfera pública-política. ${ }^{42}$

Los estudiosos de las ciencias sociales interesados en este fenómeno pueden proponer nuevas herramientas conceptuales. El periodismo cívico es un concepto propuesto por Peter Dahlgren (1998:89-100) como herramienta analítica que, desde los frentes legislativos y académicos, pretende hacer frente a la multiplicación de los géneros populares de la televisión comercial y subsanar, en alguna medida, la ausencia de políticas públicas estatales en materia de cultura y entretenimiento.

En este contexto, los investigadores sociales en México podríamos tratar de buscar el apoyo institucional y político para apostarle a una práctica periodística de investigación que haga evidente la incómoda relación que se experimenta como miembro de esta sociedad civil y consumidora, entre un longevo y desprestigiado periodismo de carácter estatal, poco distanciado de las cúpulas del poder económico y político, y

$\overline{42}$ En el particular caso mexicano, el divorcio entre la orientación social de la televisión y los públicos se hace patente por el tipo de cultura política que vive la mayor parte de los mexicanos, alejados del interés por la esfera pública-política, a la que accede sólo una relativa minoría con escolaridad universitaria. De ahí que se haya facilitado la disolución de las fronteras entre los géneros periodísticos serios y los populares pues, ante el éxito de los segundos, los primeros han adoptado sus formatos y efectos audiovisuales. 
un renovado, dinámico y vigoroso periodismo popular orientado, según sus productores, al aparente inocuo deber de "entretener" a las masas para ayudarlas a evadir su dura realidad cotidiana. ${ }^{43}$

Una propuesta a futuro, que se deriva de lo antes expuesto, sería dejar de concebir en forma aislada y totalizante el derecho a la información de los receptores de los medios y, en cambio, concebir como complementarios a éste, los derechos al honor, a la intimidad, a la vida privada y a la imagen, tanto de la gente ordinaria como de las celebridades (políticos y artistas), cuya vida privada es la materia prima de la programación descrita.

Asimismo, sería necesario hacer diagnósticos precisos acerca de los mecanismos internos de producción de esta plataforma televisual y de las condiciones socio-históricas que hacen viable su recepción exitosa, a fin de evitar generalizar y moralizar a partir de los buenos deseos de justicia y democracia de diversos grupos de la sociedad civil (incluyendo a los investigadores académicos). En cambio, sería deseable que a partir de la adecuada aplicación y diseño de técnicas etnográficas, los estudiosos de las ciencias sociales se vieran obligados a particularizar los contextos que hacen posible tanto la producción como la aceptación social de este tipo de emisiones que se consideran ajenas al bien público y que crecientemente resultan vitales para satisfacer los intereses del poderoso mercado mediático con una cobertura mundial.

$\overline{43}$ Emilio Azcárraga Milmo, extinto jerarca de la industria comercial mexicana de televisión, definió a su señal abierta como una televisión hecha para ayudar a una "clase modesta muy jodida" a evadir su dura realidad. Cfr. Reportaje de Carlos Monsiváis en la revista Proceso de mayo de 1993, citada en la hemerografía. 


\section{BIBLIOGRAFÍA}

ANG, I. (1998) "The performance of the sponge: mass communication theory enters the postmodern world", en Brants, H., Hermes, J, \& van Zoonen, L. (eds.) The Media in Question: popular cultures and public interests. London, California, New Delhi: Sage Publications.

AZURMENDI, Ana (1998) El derecho a la propia imagen: su identidad y aproximación al derecho a la información, editado en México por la universidad Iberoamericana-México y la Fundación Manuel Buendía.

BOURDIEU, Pierre (1997) Sobre la televisión. Barcelona. Anagrama. Col. Argumentos.

BRANTS, H., Hermes, J, \& van Zoonen, L. (eds.) (1998). The Media in Question: popular cultures and public interests. London, California, New Delhi: Sage Publications.

DAHLGREN, Peter (1998) "Enhancing the civil ideal in television journalism", en Brants, H., Hermes, J, \& van Zoonen, L. (eds.) The Media in Question: popular cultures and public interests. London, California, New Delhi: Sage Publications.

DENNIS, Gillmor y Glasser (eds.) (1989). Media freedom and accountability. New York. Greenwood Press.

FERNÁNDEZ C., Fátima (2002) La responsabilidad de los medios de comunicación. México, Paidós.

GAMSON, J. (1998) Freaks talk back. Tabloid talk shows and sexual nonconformity, USA, University of Chicago Press.

GERBNER, G. (1998) "Stories of violence and the public interest", en Brants, H., Hermes, J, \& van Zoonen, L. (eds.) The Media in Question: popular cultures and public interests. London, California, New Delhi: Sage Publications.

GERBNER, Mowlana y Nordenstreng (eds.) (1993) The global media debate: Its rise, fall and renewal. Norwood: Ablex.

GOLDING, Peter (1998) "New technologies and old problems: evaluating and regulating media performance in the information age", en Brants, H., Hermes, J, \& van Zoonen, L. (eds.) The Media in Question: popular cultures and public interests. London, California, New Delhi: Sage Publications.

GómEZ, G. y Renero, M. (2003) Tv Global, espectáculos Locales, El género de realidad en México y España, México, Universidad de Guadalajara.

HAMELINK, C. (1998) "World communication: conflicting aspirations for the twenty-first century”, en Brants, H., Hermes, J, \& van Zoonen, L. (eds.) The Media in Question: popular cultures and public interests. London, California, New Delhi: Sage Publications.

NORDENSTRENG, K. (1995) Toward global content analysis and media criticism, en Communication Institute for Online Scholarship, Inc., Universidad de Tampere. 
RENERO, M. (2002) "Hablar de los Hablantes. Aproximación al discurso de la prensa escrita mexicana acerca del talk show", en Orozco, G. (coord.) Recepción y Mediaciones. Casos de investigación en América Latina, Buenos Aires, Ed. Norma. Colección Enciclopedia Latinoamericana de Sociocultura y Comunicación.

SARAlegui, Cristina (2001) Confesiones de una rubia. Buenos Aires. Ed. Norma.

VAN ZOONEN, L. (1998) "The ethics of making private life public", en Brants, H., Hermes, J, \& van Zoonen, L. (eds.) The Media in Question: popular cultures and public interests. London, California, New Delhi: Sage Publications.

WIETEN, J. (1998) "Reality television and social responsibility theory", en Brants, H., Hermes, J, \& van Zoonen, L. (eds.) The Media in Question: popular cultures and public interests. London, California, New Delhi: Sage Publications.

\section{HEMEROGRAFÍA}

FERNÁNDEZ, José Antonio (2000) Entrevista a Federico Wilkins, en la revista de espectáculos Telemundo, octubre.

GARCÍA, M. G. y Renero, M. (1996) ““A favor de lo mejor’ ¿Para quién?: comentarios en torno a la campaña de las organizaciones coordinadas para mejorar los medios de comunicación", revista Comunicación y Sociedad, Núm. 28. DECS. Universidad de Guadalajara, septiembre-diciembre.

GÓMEZ, Gabriela (2002) "El reality show como constructor de la realidad social local. El caso de Ciudad Desnuda Jalisco", tesis de Maestría en Ciencias Sociales. DECS. Universidad de Guadalajara, México, enero.

GONZÁLEZ, Fernando (1993) Entrevistado por el diario Siglo 21 de Guadalajara, 30 de marzo

JOYNER P.P. y Dominick, J.R. (1994) "Pulp pulpits: self disclosure on 'Donahue"”, en Journal of Communication, 44 (4), otoño.

MONSIVÁIS, Carlos (1993) "Cristina, entre el derecho a la privacidad y el rompimiento de tabúes”, en semanario Proceso, Núm 863, México D.F., 17 de mayo.

— (1998) "De la sociedad del espectáculo", diario Público, Guadalajara, 26 de julio.

RENERO, Martha (2003) "La vida privada como espectáculo público. El talk show en México", tesis de Doctorado en Ciencias Sociales, Universidad de Guadalajara, México. Apuntes de práctica de campo, agosto.

WHITE, Robert (ed.). (1984) "Violence in the media", revista Communication Research Trends. Centre for the Study of Communication and Culture. London. Vol. 5, Núm. 4. 


\section{Notas de prensa}

Diario La Jornada.

s/a. (2000) "Tv Azteca difundió un robo actuado", nota en contraportada, 5 de julio.

s/a. (2000) "Productor de Tv Azteca ordenó grabar el video del robo simulado", nota en contraportada, 8 de julio.

LLANOS S., Raúl (2000) "Tv Azteca debe de explicar engaño: diputados”, nota en la sección La capital, p. 37, 10 de julio.

BALTAZAR, Elia (2000) "Niega el productor de Metrópolis maltratos del MP, como acusó Tv Azteca ante la CNDHDF”, nota en la sección La capital, p. 27, 15 de julio.

- (2000) "Filmó una trifulca preparada, dice ex empleado de Tv Azteca", nota en la sección La capital, p. 38, 21 de julio.

BOLAÑos S., Ángel (2000) "Habría grabado Tv Azteca más robos actuados", nota en la sección La capital, p.35, 18 de julio.

- (2000) "Funcionario de Tv Azteca pidió implicar a policías en corrupción", nota en la sección La capital, p.41, 24 de julio,

- (2000) "Demanda camarógrafo Contreras Lee a Tv Azteca por daño moral", nota en la sección La capital, p.39, 7 de septiembre.

- (2001) "Investiga la PGJDF otra denuncia contra Cosas de la Vida; ahora por difamación", nota en el diario La Jornada, p.42, sección La capital, 25 de mayo.

ELIZALDE, Triunfo (2000) "Abre la CNDH una queja de oficio contra talk shows", nota en la sección Sociedad y Justicia, p.31, 23 de septiembre.

VALADEZ R., Alfredo (2001) "Tv Azteca sobornó a tres menores infractores para que se produjeran heridas en los brazos", nota en la sección Política, p.9, 5 de enero.

VELÁZQUEZ, Miguel Ángel (2001) "Talk show de Tv Azteca, la pesadilla de un extra", nota en el diario La Jornada, p. 37, columna "Ciudad Perdida", sección La capital, 24 de mayo.

VILLAMIL, Genaro (2001) "Tv Azteca, ética y comercialización”, nota en el diario La Jornada, p.39, sección Sociedad y Justicia, 29 de abril.

\section{OTROS DIARIOS Y REVISTAS}

MACÍAS P., Salvador (2001) "Participó en un "talk show" y ahora todos lo desprecian”, nota del diario Excélsior de la ciudad de México, 21 de febrero. Misma nota reproducida y ampliada por el mismo autor y título en la revista mensual Etcétera de marzo de 2001, p. 67.

CANO M., Deyanira (2001) “A cambio de un viaje fingió ser sufrida esposa”, nota en revista Etcétera, p.66, marzo. 